\title{
Impact of the Field Winding Interturn Short-Circuit Position on Rotor Vibration Properties in Synchronous Generators
}

\author{
Xing-Hua Yuan $\mathbb{D}^{1},{ }^{1}$ Yu-Ling He $\mathbb{D}^{1},{ }^{1}$ Man-Yu Liu, ${ }^{2}$ Hui Wang, ${ }^{3}$ Shu-Ting Wan, \\ and Gaurang Vakil ${ }^{4}$ \\ ${ }^{1}$ Department of Mechanical Engineering, \\ Hebei Provincial Key Lab of Electric Power Equipment Maintenance and Failure Prevention, \\ North China Electric Power University, Baoding 071003, China \\ ${ }^{2}$ State Grid Beijing Electric Power Research Institute, Beijing 100000, China \\ ${ }^{3}$ Department of Electrical Engineering, North China Electric Power University, Baoding 071003, China \\ ${ }^{4}$ Department of Electrical and Electronics Engineering, University of Nottingham, NG7 2RD, Nottingham, UK
}

Correspondence should be addressed to Yu-Ling He; heyuling1@163.com

Received 19 October 2021; Accepted 22 November 2021; Published 30 November 2021

Academic Editor: Xian-Bo Wang

Copyright (C) 2021 Xing-Hua Yuan et al. This is an open access article distributed under the Creative Commons Attribution License, which permits unrestricted use, distribution, and reproduction in any medium, provided the original work is properly cited.

\begin{abstract}
This paper investigates the effect of the field winding interturn short-circuit (FWISC) position on the rotor vibration properties in turbo generators. Different from the previous studies which focused on the influence of the short-circuit degree, this work pays much attention to the impact of the short-circuit position on the rotor unbalanced magnetic pull (UMP) properties and vibration characteristics. The theoretical UMP model is firstly deduced based on the analysis of the magnetic flux density (MFD) variation. Then, the finite element analysis (FEA) is performed to calculate the UMP data. Finally, the rotor vibrations are tested on a CS-5 prototype generator which has two poles and a rated capacity of $5 \mathrm{kVA}$. It is shown that the occurrence of FWISC will greatly increase the UMP as well as the rotor vibration. In addition to the short-circuit degree, the short-circuit position will also affect the UMP and vibration. The nearer the short-circuit position is to the big rotor teeth, the larger the UMP and vibration will be. The proposed study in this paper will be beneficial for the monitoring and diagnosis of FWISC faults.
\end{abstract}

\section{Introduction}

Field winding interturn short circuit (FWISC) is a common electrical fault in synchronous generators and has been studied by scholars for a long time since the 1960s [1]. This fault can be caused due to many reasons [2] such as residual particles in the slot and the interturn insulation degrading. Luckily, it will not significantly affect the performance of the generator when the short-circuit degree is light. However, this fault will develop into an earth fault if without carrying out proper measures.

Scholars have made a lot of efforts in studying the electromagnetic properties. For instance, Dirani et al. studied the impact of the FWISC degree on the primary parameters such as the radial magnetic flux density (MFD), the radial force density, and the UMP of a 74 MVA industrial large hydrogenerator with 76 poles [3]. As a supplement, the authors of this paper have also studied the magnetic field variation due to FWISC, finding that both the short-circuit degree and the short-circuit position will affect MFD $[4,5]$ and the stator voltage/current [6]. It is found that the occurrence of FWISC will generally decrease the MFD $[4,5]$ and break the symmetric components of the stator voltage/ current into asymmetric ones [6].

Besides the magnetic and the electrical parameters, scholars have also found that FWISC will still affect the frame/housing vibrations $[7,8]$ and the stator winding vibrations $[9,10]$. Since the vibration and the electromagnetic torque are both in proportion to the square of the magnetic flux which can be considerable by FWISC, not only the 
stator/housing vibration but also the electromagnetic torque will be influenced by such a fault. Typically, Hao et al. investigated the electromagnetic torque characteristics before and after FWISC [11], indicating that the torque ripples will be greatly strengthened by the interturn short circuit.

Based on the faulty electromagnetic properties, scholars and engineers have proposed various methods to monitor and diagnose the FWISC fault. For instance, Yucai and Yonggang calculated the difference between the virtual power and the actual electromagnetic power to detect the occurrence and the FWISC degree in turbine generators [12], while Hao et al. employed the rotor and the stator current to monitor the very fault based on multiloop theory [13]. To distinguish the rotor winding fault from the mechanical faults, Salomon et al. used the method of symmetrical components and proposed a simple, low-cost, and low intrusive condition monitoring system which only relied on stator electrical quantities [6], while more scholars alternatively employed the magnetic flux difference for pattern recognition [14].

It has been found that the saturable effect will affect the electromagnetic parameters due to its nonlinear effect [15]. As a typical technical method, Milasi et al. [16], Ehya and Nysveen [14], Yun et al. [17], and Yucai et al. [18] employed the noninvasive flux sensors to detect the FWISC fault in salient-pole $[14,16,17]$ and nonsalient-pole synchronous generators [18], respectively, while Valavi et al. used the spectral analysis of stator voltage and current to diagnose the very fault [19]. Additionally, Li et al. used the circulating current inside the stator parallel branches to detect the interturn short circuit [20-22], while He et al. [23] and Wan et al. [22, 24] employed the stator and rotor vibrations to diagnose FWISC. To detect FWISC more quickly, intelligent methods such as digital neural network [25] are employed and have gained a satisfied effect.

The aforementioned studies have set up a good basis for the FWISC fault detection and monitoring. However, most of the studies primarily focus on the electromagnetic property variations due to the short-circuit degree, while the impact of the short-circuit position on the key electromechanical characteristics such as the rotor vibration has been rarely investigated in detail. As an improvement, in this paper, we focus on the rotor UMP and vibration properties under varied FWISC position cases in synchronous generators. Specifically, a nonsalient-pole prototype generator, which has two poles and a rated capacity of $5 \mathrm{kVA}$, is taken as the study object. The remainder of this paper is arranged as follows. Section 2 puts forward the theoretical analysis model of the rotor UMP, while Section 3 carries out the finite element analysis (FEA) and the experimental study on the CS-5 prototype generator to obtain the UMP values and the rotor vibrations for a validation. Finally, the main conclusions based on the theoretical analysis, FEA calculation, and experimental studies are drawn up in Section 4.

\section{Theoretical Model}

In turbo generators, the field winding is connected in series and embedded in the rotor slots, as indicated in Figures 1(a) and 1(b). As FWISC occurs, the exciting current $I_{f}$ will no longer pass through the shorted turns, which means the current inside the shorted turns will be reduced to almost zero. Consequently, the rotor magnetomotive force (MMF) will be decreased due to the reduction of the exciting turns, as illustrated in Figure 1(c). Assuming that FWISC occurs in slot 1-1' (position 1) and 3-3' (position 2), respectively, with the same short-circuit turns, it is obvious that MMF will be decreased more in position 2 since $\alpha_{r 2}$ is larger than $\alpha_{r 1}$. In Figure 1(c), the shadows represent the reduced amounts of MMF for the two different shorted position cases.

To concisely study the impact of FWISC on MMF, we add reversed $I_{f}$ to the shorted turns so that the final current in these shorted turns can be turned to zero. Then, the analysis on the effect of the short circuit can be changed to the investigation on the impact of such a reversed current. According to the Gauss flux theorem, the positive magnetic flux produced by the reversed current should be equal to the negative magnetic flux, i.e., the yellow part in Figure 1(e) should have the same area as the green part. Then, the amplitudes of the yellow part and the green part can be calculated; see Figure 1(e), where $n_{m}$ is the number of shortcircuit turns. Finally, the rotor MMF will be changed from Figure 1(d) to Figure 1(f). More details about the calculation process can be found in [4].

As investigated in $[4,5]$, the rotor MMF $F_{r}$ is $(90+\psi)$ degree in front of the stator $\operatorname{MMF} F_{s}$, as indicated in Figure 2(a), and the composite MMF can be written as

$$
\left\{\begin{array}{l}
f\left(\alpha_{m}, t\right)=F_{s} \cos \left(\omega t-\alpha_{m}-\psi-0.5 \pi\right)+F_{r} \cos \left(\omega t-\alpha_{m}\right)=F_{c} \cos \left(\omega t-\alpha_{m}-\beta\right) \\
F_{c}=\sqrt{F_{s}^{2} \cos ^{2} \psi+\left(F_{r}-F_{s} \sin \psi\right)^{2}} \\
\beta=\arctan \frac{F_{s} \cos \psi}{F_{r}-F_{s} \sin \psi}
\end{array}\right.
$$

where $\alpha_{m}$ is the mechanical angle to indicate the circumferential position of the air gap, $\omega$ is the electrical angular frequency (for turbo generators, it is equal to the mechanical angular frequency of the rotor $\omega_{r}$ ), $\psi$ is the internal power angle of the generator, and $F_{c}$ is the vector summation of $F_{s}$ and $F_{r}$. Since the occurrence of FWISC decreases $F_{r}$, the 


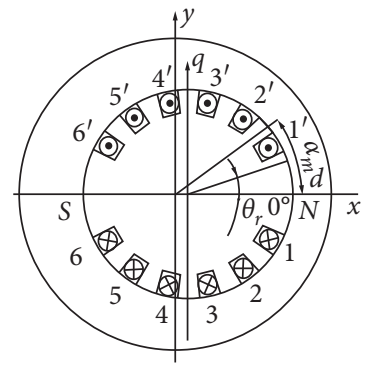

(a)

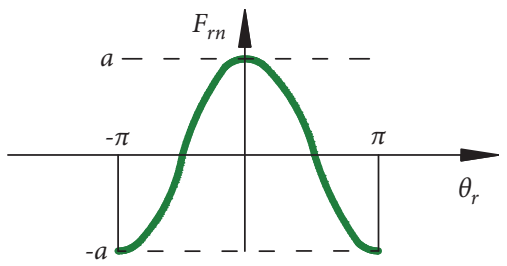

(d)

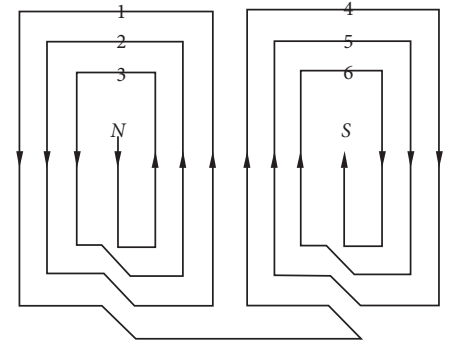

(b)

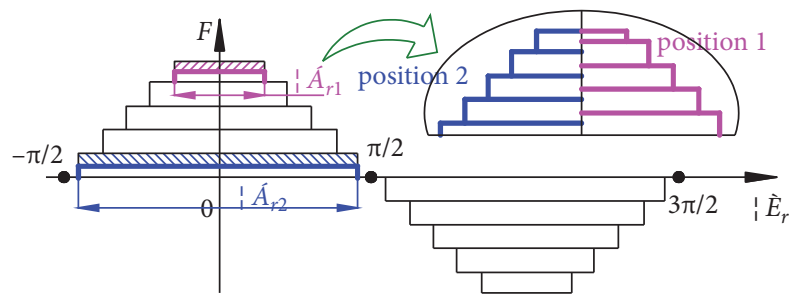

(c)

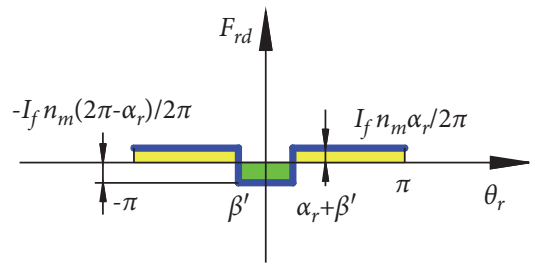

(e)

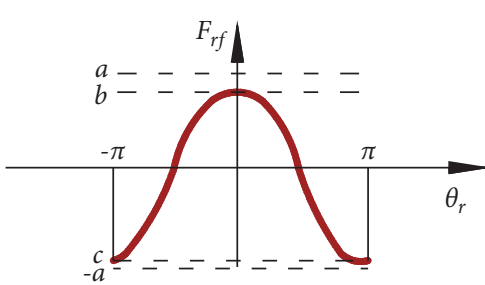

(f)

FIgURE 1: Rotor MMF variation: (a) rotor structure, (b) field winding connection, (c) MMF reduction due to FWISC in two different positions, (d) normal rotor MMF, (e) inversed MMF by short-circuit turns, and (f) MMF after FWISC.

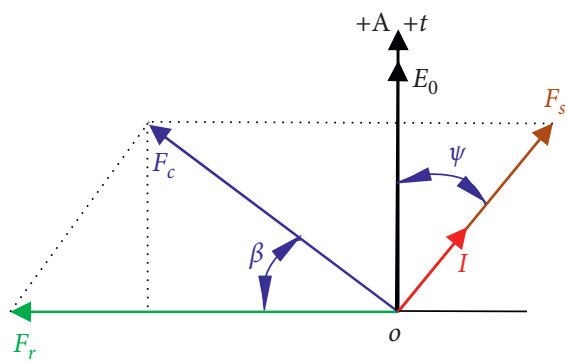

(a)

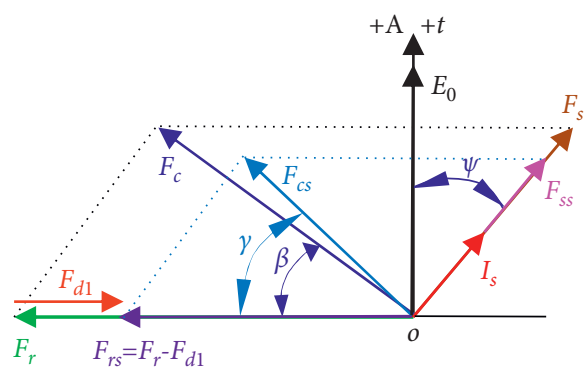

(b)

Figure 2: Fundamental frequency MMFs (a) before and (b) after FWISC.

stator MMF will also be reduced, as illustrated in Figure 2(b). Consequently, the composite MMF will be decreased from $F_{c}$ to $F_{c s}$.

Since different MMF harmonics (both the rotor MMF and the stator MMF) rotate at varied speeds, for the sake of clarification, in Figure 2, all of the MMFs are the 1st ones. The higher-order harmonics have the similar situation as the 1st ones and therefore are not illustrated in this figure due to the limitation of the space. In Figure 2(b), $F_{d 1}$ is the 1 st harmonic of the inversed MMF produced by the shortcircuit turns, and it can be obtained based on the performance of Fourier series decomposition.

Then, the composite MMF illustrated in Figure 2(b) can be written as

$$
f\left(\alpha_{m}, t\right)=F_{s s} \cos \left(\omega t-\alpha_{m}-\psi-0.5 \pi\right)+\left(F_{r}-F_{d 1}\right) \cos \left(\omega t-\alpha_{m}\right)=F_{c s} \cos \left(\omega t-\alpha_{m}-\gamma\right)
$$

To indicate the short-circuit position, the angle between the two slots where FWISC takes place is employed; see $\alpha_{r}$ in Figures 1(c) and 1(e). The larger value of $\alpha_{r}$ indicates that the short-circuit position moves away farther from the big tooth of the rotor. Qualitatively, the larger $\alpha_{r}$ is, the larger $F_{d 1}$ will be, but, on the contrary, the smaller $F_{c s}$ will be.

The unbalanced magnetic pull (UMP) on the rotor can be obtained via $[22,24]$. 


$$
\left\{\begin{array}{l}
F_{X}=\operatorname{LR} \int_{0}^{2 \pi} q\left(\alpha_{m}, t\right) \cos \alpha_{m} \mathrm{~d} \alpha_{m} \\
F_{Y}=\operatorname{LR} \int_{0}^{2 \pi} q\left(\alpha_{m}, t\right) \sin \alpha_{m} \mathrm{~d} \alpha_{m} \\
q\left(\alpha_{m}, t\right)=\frac{B^{2}\left(\alpha_{m}, t\right)}{2 \mu_{0}} \\
B\left(\alpha_{m}, t\right)=f\left(\alpha_{m}, t\right) \Lambda_{0}
\end{array}\right.
$$

where $F_{X}$ and $F_{Y}$ are the UMPs in the $X$ (horizontal) direction and the $Y$ (vertical) direction, respectively, $q$ is the magnetic pull per unit area, $B$ is the magnetic flux density (MFD), and $\Lambda_{0}$ is the permeance per unit area.

Feed (1) and (2) into (3), respectively; the rotor UMP in normal and FWISC cases can be written as

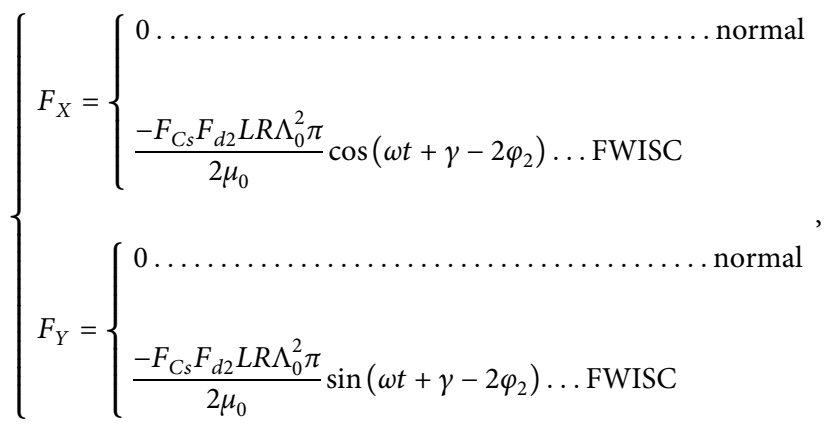

where $F_{d 2}$ is the 2nd harmonic of the reversed MMF produced by the short-circuit turns, $F_{c s}$ is the composite MMF in the FWISC case (see Figure 2(b)), and $\varphi_{2}$ is the angle between $F_{d 2}$ and the $X$-axis.

According to (4), the occurrence of FWISC will bring in the extra 1st UMP harmonic to the rotor, resulting in the intensified vibration at $\omega$. Moreover, it is suggested from Figure 1(c), Figure 2(b), and equation (3) that the increment of $\alpha_{r}$ will decrease $F_{c s}$ and $B$. Consequently, the UMPs $F_{X}$ and $F_{Y}$ will also be decreased. Briefly, for the rotor UMP and vibration, the nearer short-circuit position to the big tooth with the same short-circuit degree has the similar effect as the severer shortcircuit degree at the same shorted position. The short-circuit degree is defined as

$$
f d=\frac{n_{m}}{N} \times 100 \%,
$$

where $n_{m}$ is the number of short-circuit turns, while $N$ is the number of total exciting turns.

\section{FEA and Experimental Study}

3.1. FEA and Experimental Setup. FEA and experiments are carried out on a CS-5 prototype generator in the State Key Laboratory of Alternate Electrical Power Systems with Renewable Energy Sources, P. R. China, as illustrated in Figure 3(a). The prototype generator has two poles and a rated rotating speed of $3000 \mathrm{rpm}$. The primary parameters of the prototype generator are listed in Table 1.
On the generator, there is a plate with several interturn short-circuit taps for the field windings, as shown in Figure 3(a). During the experiment, $L_{0}-L_{1}, L_{1}-L_{2}$, and $L_{2}-L_{3}$ are connected, respectively, to simulate $5 \%$ FWISC at varied positions. Two PCB accelerometers with very little volume and mass are fixed to the horizontal direction and the vertical direction of the bearing block, respectively, to test the vibration signals of the rotor, as shown in Figure 3(b).

2D FEA is carried out, with the parameter settings the same as the experimental ones. The finite element models are illustrated in Figure 3(c), while the external coupling circuit models are shown in Figure 3(d). During FEA, four groups of calculations are carried out:

(1) Normal condition: no FWISC is set, as illustrated in the first figure in Figure 3(c). The data are collected as the reference for further comparison with the faulty cases.

(2) $5 \%$ FWISC at position 1 with minimal $\alpha_{r}$ (hereafter, it is written as FWISC5\%-1), as illustrated in the second figure in Figure 3(c).

(3) $5 \%$ FWISC at position 2 (hereafter, it is written as FWISC5\%-2), as illustrated in the third figure in Figure 3(c).

(4) $5 \%$ FWISC at position 3 with maximal $\alpha_{r}$ (hereafter, it is written as FWISC5\%-3), as illustrated in the fourth figure in Figure 3(c).

The aforementioned four cases are also carried out for at least three times in the experiment, respectively, to get sufficient test data. The experimental results show a general consistency, with only small value variations in the vibration amplitudes. More details about the FEA data and the experimental results can be specifically found in Section 3.2.

3.2. Results and Discussion. The MFD and the phase current variations before and after FWISC are illustrated in Figures 4(a) and 4(b), respectively. It is shown that MFD and the phase current at FWISC cases will have smaller amplitudes than the normal condition. As the short circuit goes away from the big tooth, namely, $\alpha_{r}$ increases, MFD as well as the phase current will be decreased. The larger $\alpha_{r}$ is, the more MFD/current will be decreased. Such a result is consistent with Figures 1(c)-1(f).

The UMPs in the $X$-direction and $Y$-direction by FEA are illustrated in Figures 5(a) and 5(b), respectively, while the tested vibrations in $X$ - and $Y$-directions are indicated in Figures 6(a) and $6(\mathrm{~b})$, respectively. It is shown that, as the short-circuit position moves away from the big tooth, namely, $\alpha_{r}$ goes bigger, the UMPs in both $X$-direction and $Y$-direction will be decreased. Correspondingly, the rotor vibrations in $X$ - and $Y$ directions will also be decreased. The very reason is that the magnetic pull is in proportion to MFD, as indicated in equation (3); bigger $\alpha_{r}$ will make MFD to decrease more, as illustrated in Figures $1(\mathrm{c})$ and 1(e). Although the rotor UMPs and the vibrations will be decreased as the increment of $\alpha_{r}$ they are still larger than those in the normal condition since the occurrence of FWISC will break down the magnetic pull balance between the two poles. 


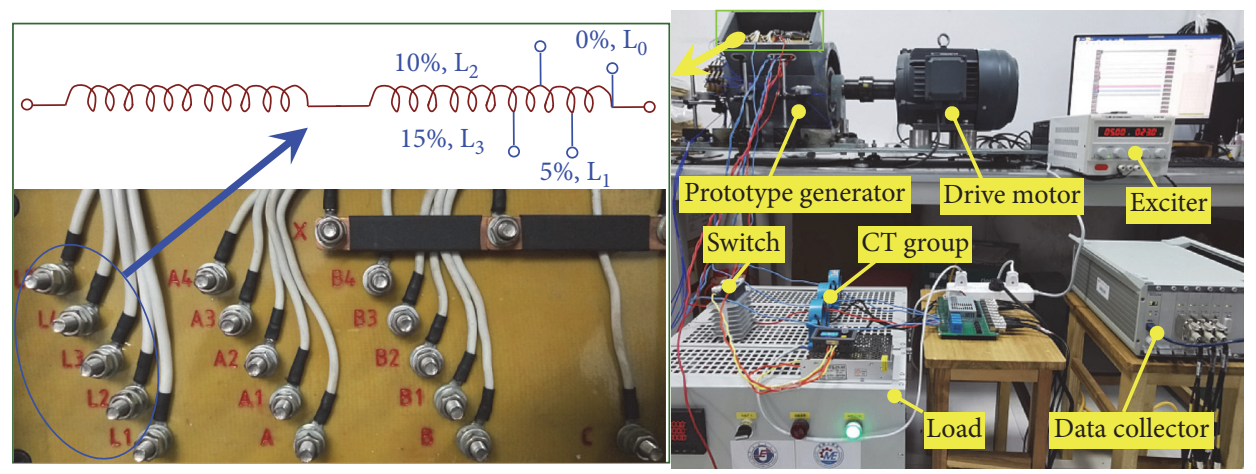

(a)

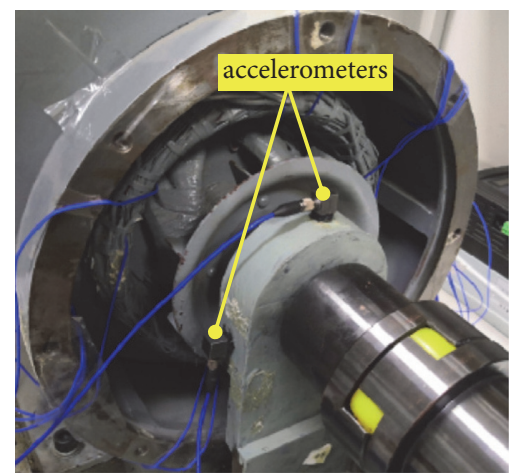

(b)

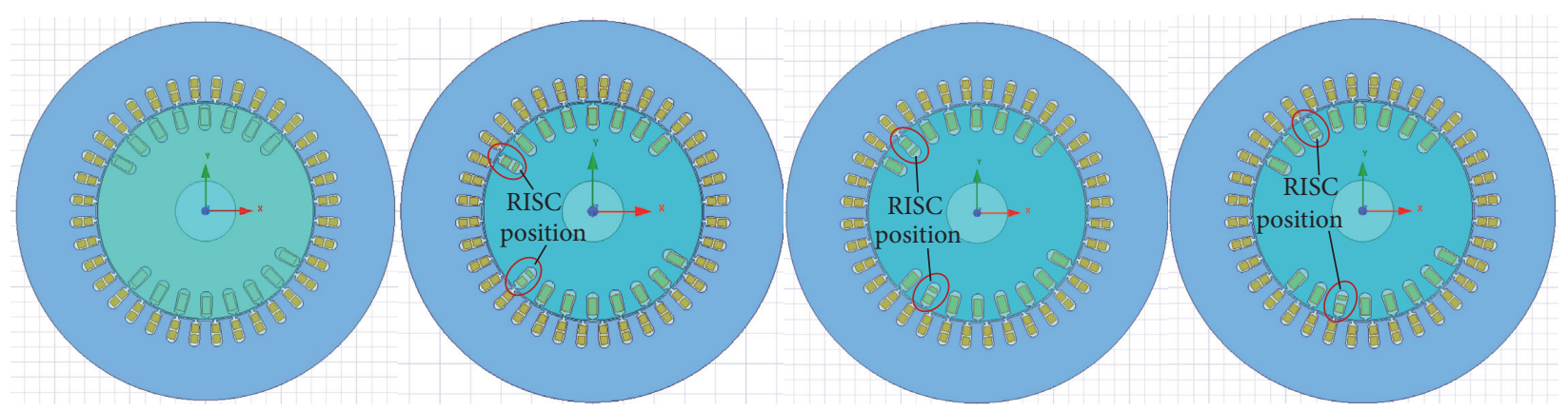

(c)

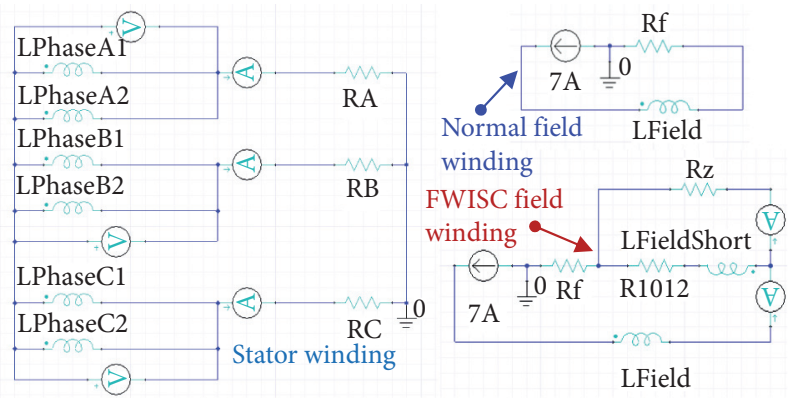

(d)

FIGURE 3: Experiment and FEA setup on a CS-5 prototype generator: (a) picture of the generator set, (b) accelerometers' setup for the rotor vibration test, (c) FE models: from left to right, for normal condition and FWISC cases at position 1, 2, and 3, respectively, and (d) external coupling winding circuits.

The UMP and the vibration spectra are shown in Figures 5(c) and 5(d) and Figures 6(c) and 6(d), respectively. As indicated in Figures 5(c) and 5(d), the primary UMP components are the odd harmonics, primarily the 1st, 5 th, and 7 th.
Such a result is in good accordance with equation (4). In equation (4), the UMP result mainly takes into account the interaction between the 1st composite MMF and the 2nd inversed MMF harmonic $\left(F_{d 2}\right)$, while actually, there are still 
TABLE 1: Key parameters of the CS-5 prototype generator.

\begin{tabular}{lc}
\hline Parameter & Value \\
\hline Rated capacity & $5 \mathrm{KVA}$ \\
Rated voltage & $380 \mathrm{v}$ \\
Rated rotating speed & $3000 \mathrm{rpm}$ \\
Number of pole pairs & 1 \\
Connection mode of the stator winding & $2 \mathrm{Y}$ \\
Pitch & 14 \\
Number of stator slots & 36 \\
Power factor & 0.8 \\
Number of rotor slots & 16 \\
Number of turns per rotor slot & 60 \\
Outer diameter of the rotor & $142.6 \mathrm{~mm}$ \\
Inner diameter of the stator & $145 \mathrm{~mm}$ \\
Rated stator current & $7.6 \mathrm{~A}$ \\
Length of the stator and rotor & $130 \mathrm{~mm}$ \\
\hline
\end{tabular}

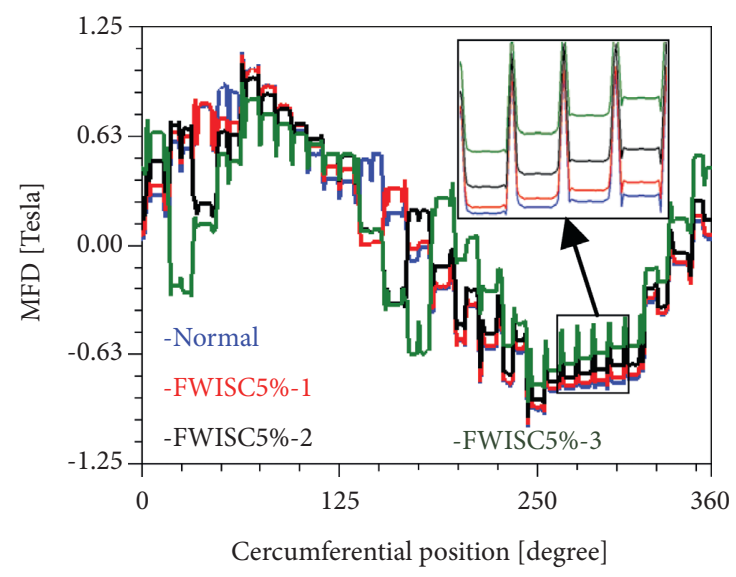

(a)

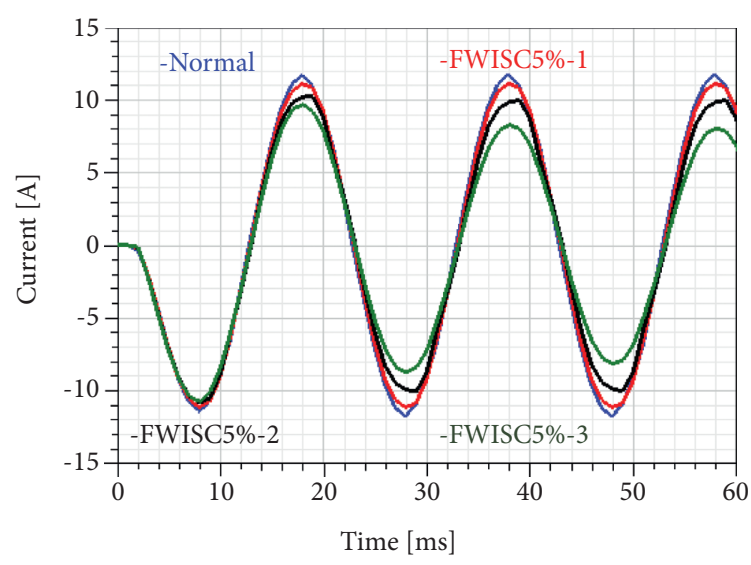

(b)

FIGURE 4: MFD and current variations for FWISC cases with varied short-circuit positions: (a) MFD and (b) phase current.

other odd composite MMF harmonics such as the 3rd, 5th, and 7 th harmonics. Consequently, the square operation in equation (3) will produce odd UMP harmonics. However, for the experimental vibration spectra, the cases are much more complex. As indicated in Figures 6(c) and 6(d), the rotor vibrations still have even harmonics in addition to the odd harmonics since the stator vibrations (mainly even harmonics) will be transferred to the rotor through the foundation and the bearings [23]. It is also suggested from Figure 6 that there are some asymmetric factors inside the generator since the rotor has vibrations of each harmonic in even normal condition. The vibration spectra in the $X$-direction do not strictly follow the theoretical developing tendency since vibration is a complex phenomenon which can be affected by many factors. However, the vibrations in the $Y$ direction present a much better result. Theoretically, the 3rd vibration harmonic should not have that large amplitude; please see Figures 6(c) and 6(d). The authors have repeated the experiments for several times but generally obtained similar data. After comprehensive analysis and test, it is found that the bearing blocks have a natural frequency at about $150 \mathrm{~Hz}$.

To more vividly present the action of the UMP on the rotor, the force distributions by FEA are illustrated in Figure 7. It is shown that, in the normal condition, the magnetic forces at the two poles are generally symmetric, as indicated in Figure 7(a). However, the occurrence of FWISC will break down such symmetry. As $\alpha_{r}$ goes bigger, namely, the short-circuit position goes farther away from the big tooth, the amplitude of the edge force will be decreased, but the general UMP (difference value of the summing edge force between two sides) on the whole rotor will be increased. Such a result is consistent with the aforementioned analysis.

Since the vibration is actually the periodic deformation/ movement with respect to a central position, the rotor deformation/movement amplitude represents the vibration amplitudes. We also carry out a quick calculation to obtain the rotor deformation under the action of the UMPs. During the calculation, we perform the approximated constraint and load on the rotor. Physically, the rotor is restrained by the bearings. However, since we carry out a $2 \mathrm{D}$ FEA in which it is hard to simulate the fix effect of the bearings in two different axial positions, we approximately fix the rotor on one side and apply the UMP on the other side, as illustrated in Figure 8(a).

The rotor deformation results at the same moment are illustrated in Figures $8(\mathrm{~b})-8(\mathrm{e})$. Since this is an equivalent fast calculation, the deformation result may not be so 


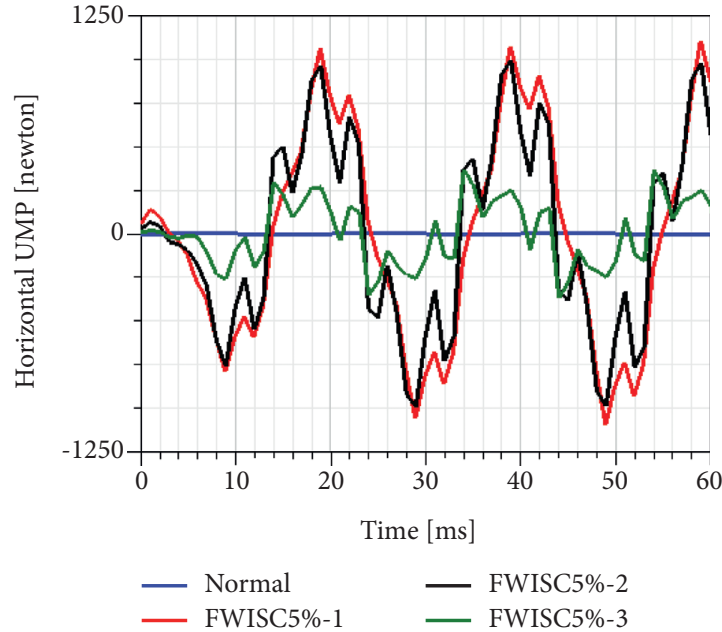

(a)

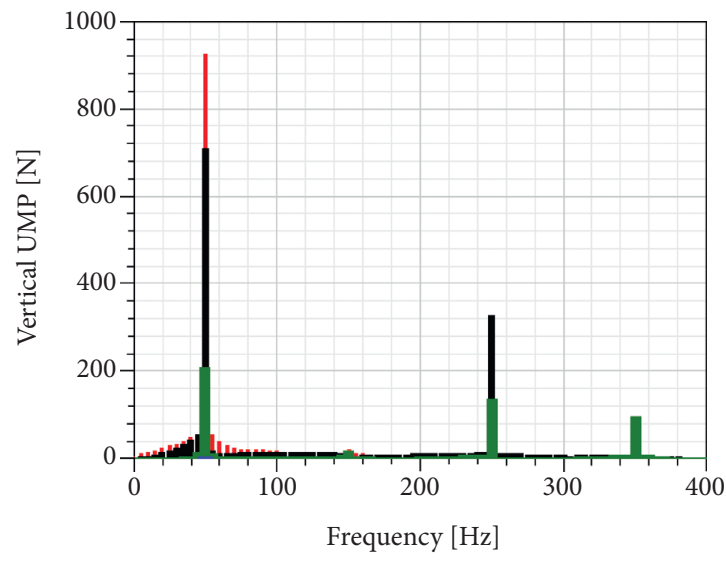

$\begin{array}{ll}\text { Normal } & - \text { FWISC5\%-2 } \\ \text { FWISC5\%-1 } & \text { FWISC5\%-3 }\end{array}$

(c)

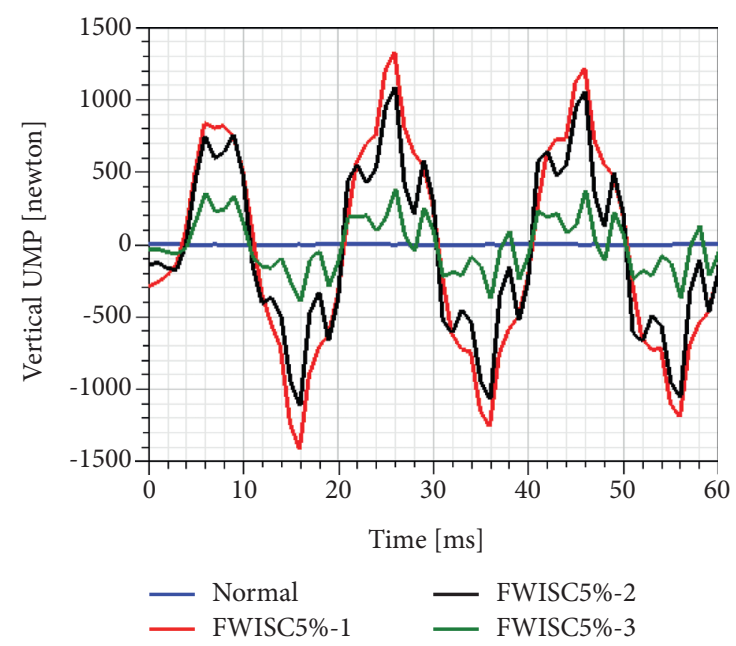

(b)

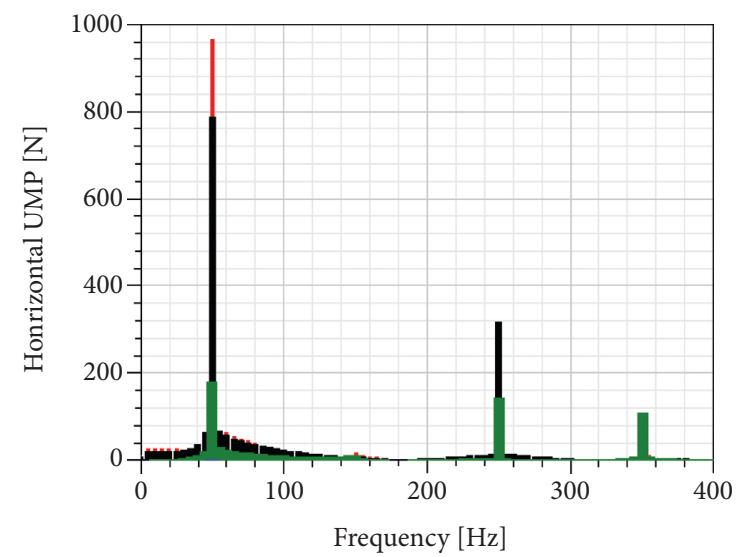

$\begin{array}{ll}- \text { Normal } & \text { FWISC5\%-2 } \\ - \text { FWISC5\%-1 } & \text { FWISC5\%-3 }\end{array}$

(d)

FIgure 5: UMPs by FEA: (a) $X$-direction curves, (b) $Y$-direction curves, (c) $X$-direction spectrum, and (d) $Y$-direction spectrum.

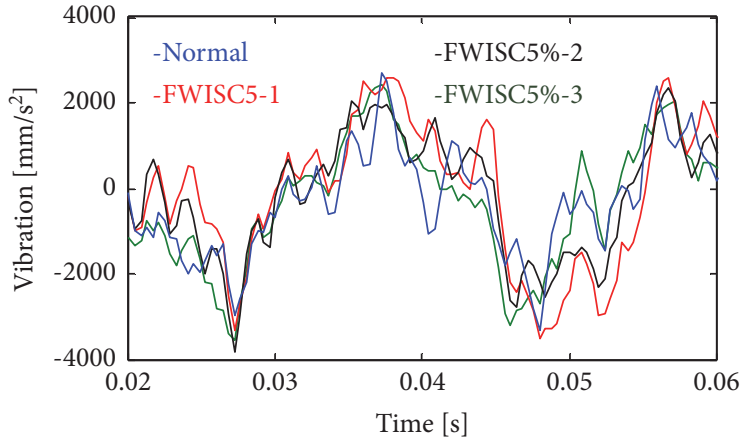

(a)

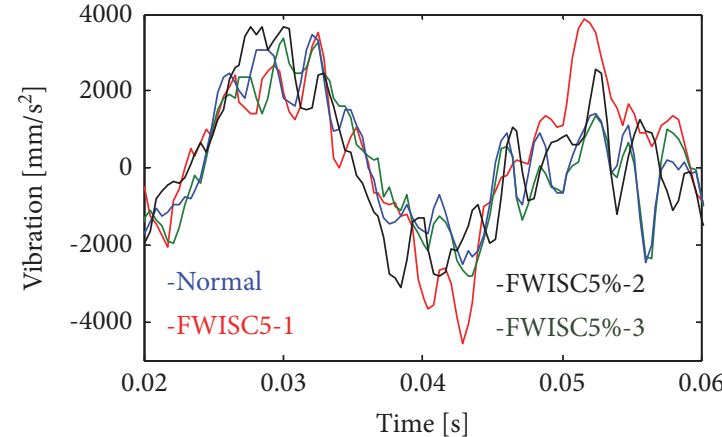

(b)

FIgURE 6: Continued. 


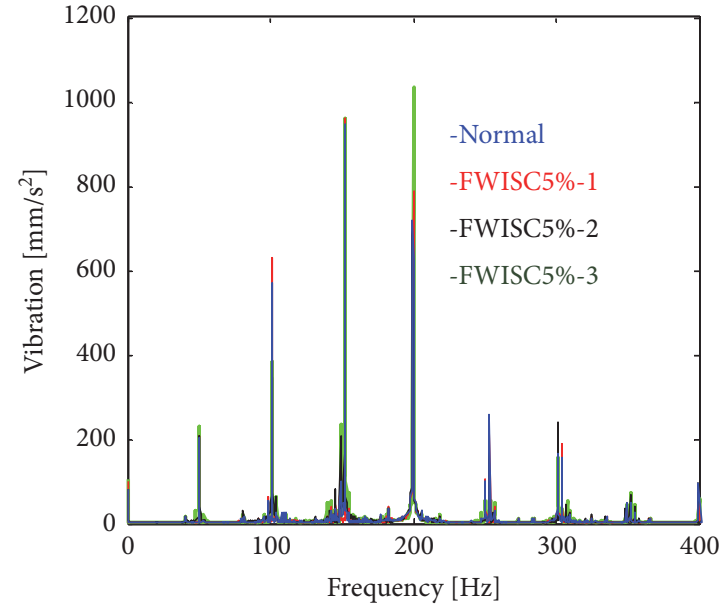

(c)

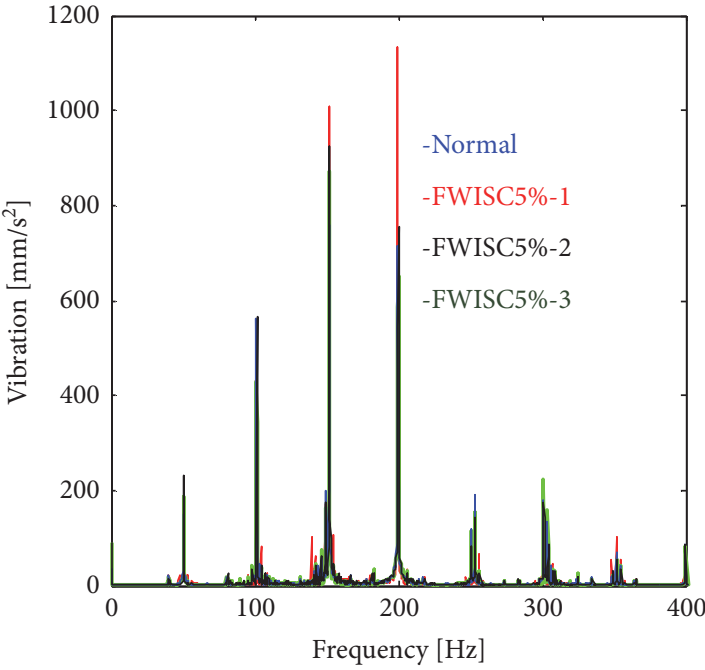

(d)

Figure 6: Vibrations by experiment: (a) X-direction curves, (b) $Y$-direction curves, (c) $X$-direction spectrum, and (d) $Y$-direction spectrum.
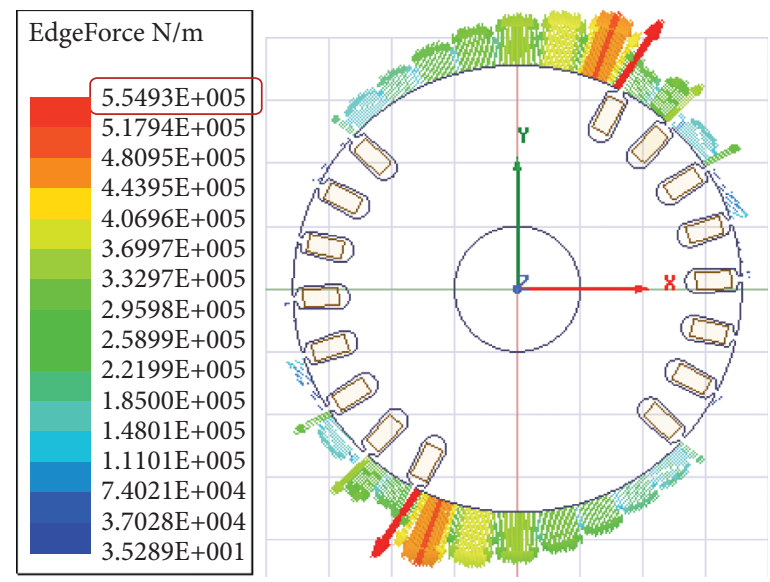

(a)

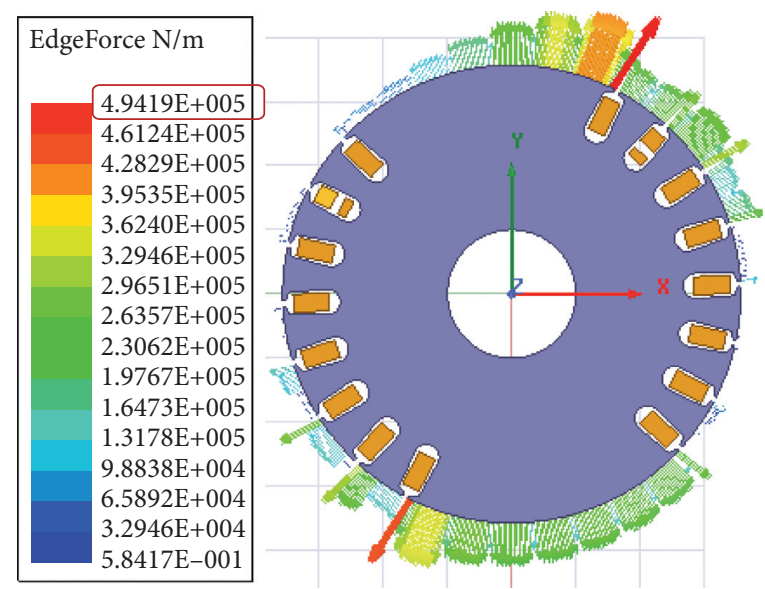

(c)

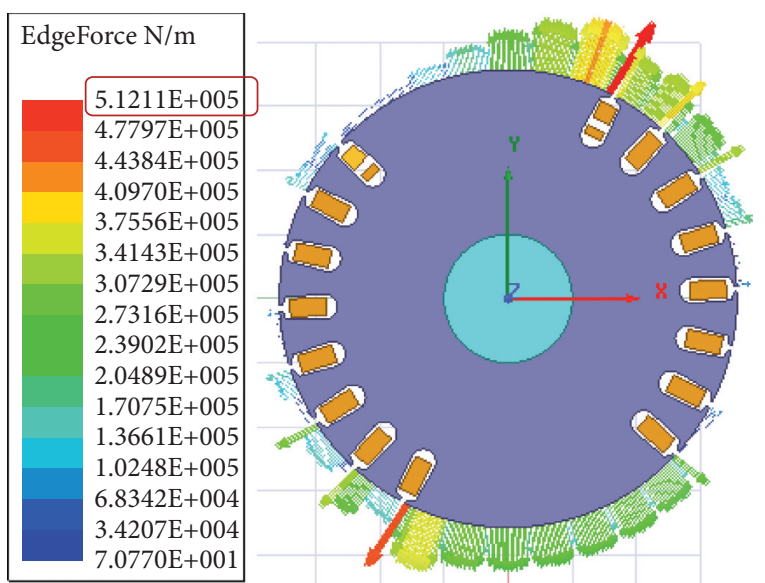

(b)
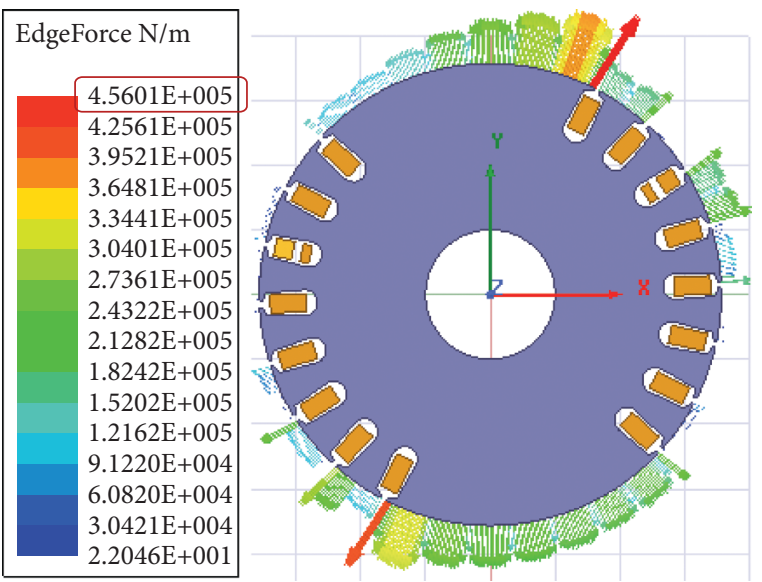

(d)

FIgURe 7: Edge force distribution at $0.2 \mathrm{~s}$ : (a) normal and (b-d) 5\% FWISC at position 1, 2, and 3, respectively. 

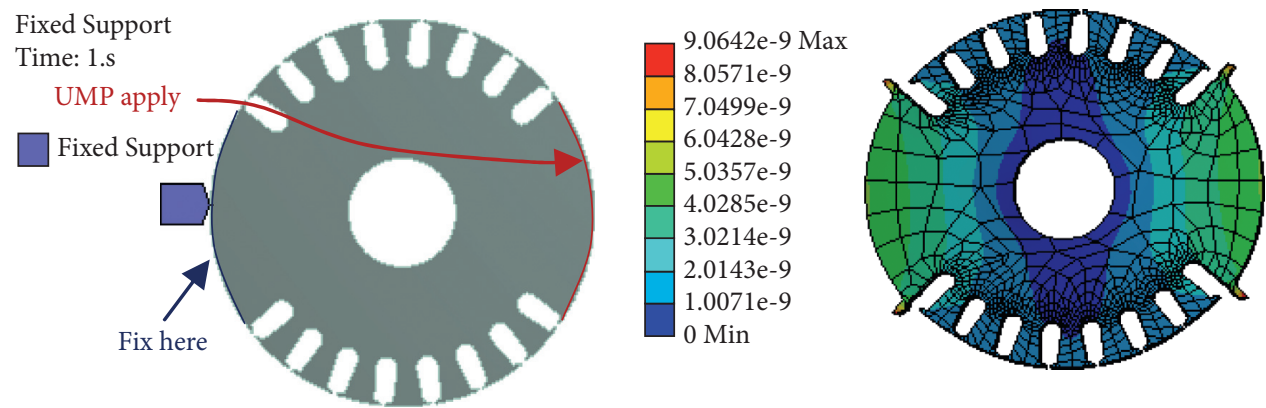

(a)
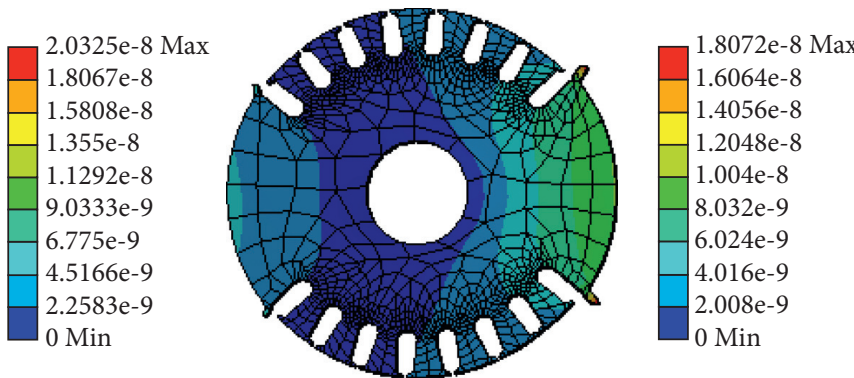

(b)

(c)

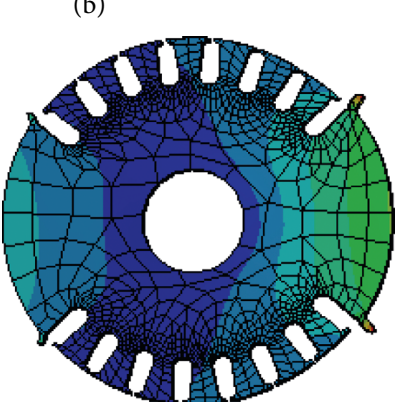

(d)

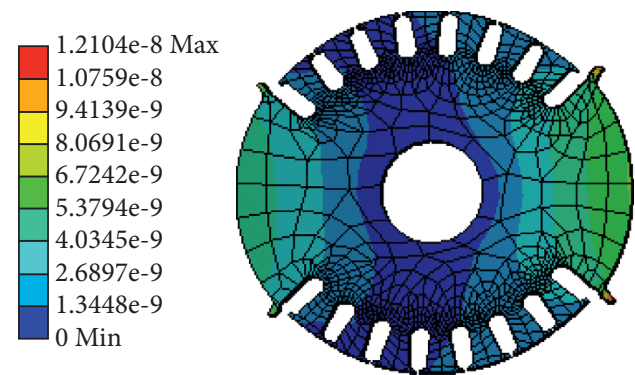

(e)

FIGURE 8: Max deformation by FEA: (a) detailed fix position and UMP apply position, (b) normal deformation, and (c-e) deformation in 5\% FWISC cases at position 1,2 , and 3 , respectively.

accurate, but the deformation tendency should be the same as the practical one. It shows that, in FWISC cases, the rotor will have a larger deformation than in the normal condition. As the short-circuit position goes farther away from the big tooth, the deformation amplitude will be decreased, indicating that the rotor vibration magnitudes will be reduced. Such a trend follows the previous analysis well.

\section{Conclusions}

This paper investigates the impact of the field winding interturn short-circuit position on the rotor UMPs and vibrations. The whole work is based on the theoretical analysis, the finite element calculation, and the experimental test. The primary contribution of this paper mainly lies in two aspects: (1) the influence of the FWISC position on MFD and the exact way about how such an influence takes place are comprehensively studied, while other research studies mainly focused on the impact of FWISC degrees; (2) the impact of the FWISC position on the rotor UMPs and vibrations is investigated, finding out the UMP/vibration developing tendency/regularity, while other scholars have rarely paid attention to this field.

The primary conclusions based on the study proposed in this work can be drawn up as follows:

(1) Normally, the rotor UMP is very little due to the symmetric distribution of the magnetic force.

(2) The occurrence of FWISC will increase the rotor UMPs in both $X$ - and $Y$-directions. Consequently, the rotor vibrations in these two directions will be amplified.

(3) As the FWISC position goes farther away from the big tooth, the rotor UMPs as well as the rotor vibrations will be decreased, but are still larger than those in the normal condition.

Since the findings in this paper include the rotor UMP/ vibration developing regularity due to varied FWISC positions, they are highly potential to be employed as a supplement to the current knowledge base and will be beneficial for the condition monitoring and the failure prevention in turbo generators. Moreover, the aforementioned study 
results can also be extended to other similar generators that have wound rotors, regardless of the pole numbers. For instance, the conclusion can be applied to the hydrogenerators which have multi-salient-poles and the nuclear turbine generators which have two nonsalient-pole pairs.

\section{Data Availability}

The data used to support the findings of this study are available from the corresponding author upon request.

\section{Conflicts of Interest}

All of the authors declare that there are no conflicts of interest regarding the publication of this paper.

\section{Acknowledgments}

This work was supported by the National Natural Science Foundation of China (51777074), the Chinese Fundamental Research Funds for the Central Universities (2017MS151), the Hebei Provincial Natural Science Foundation (E2020502032), and the Top Youth Talent Support Program of Hebei Province ([2018]-27).

\section{References}

[1] P. Hermann, R. Mahrt, and H. Doon, "Detecting and locating interturn short circuits on turbine-generator rotors," IEEE Transactions on Power Apparatus and Systems, vol. 82, no. 68, pp. 686-698, 1963.

[2] D. Albright, "Interturn short-circuit detector for turbinegenerator rotor windings," IEEE Transactions on Power Apparatus and Systems, vol. PAS-90, no. 2, pp. 478-483, 1971.

[3] H. C. Dirani, A. Merkhouf, B. Kedjar, A.-M. Giroux, and K. Al-Haddad, "Rotor interturn short circuit impact on large hydrogenerator magnetic quantities," IEEE Transactions on Industry Applications, vol. 54, no. 4, pp. 3702-3711, 2018.

[4] Y.-L. He, M.-Q. Ke, G.-J. Tang, H.-C. Jiang, and X.-H. Yuan, "Analysis and simulation on the effect of rotor interturn short circuit on magnetic flux density of turbo-generator," Journal of Electrical Engineering, vol. 67, no. 5, pp. 323-333, 2016.

[5] Y.-L. He, Y. Wang, H.-C. Jiang et al., "A novel universal model considering SAGE for MFD-based faulty property analysis under RISC in synchronous generators," IEEE Transactions on Industrial Electronics, p. 1, 2021.

[6] C. P. Salomon, W. C. Santana, G. Lambert-Torres et al., "Discrimination of synchronous machines rotor faults in electrical signature analysis based on symmetrical components," IEEE Transactions on Industry Applications, vol. 53, no. 3, pp. 3146-3155, 2017.

[7] M. Cuevas, R. Romary, J.-P. Lecointe, and T. Jacq, "Noninvasive detection of rotor short-circuit fault in synchronous machines by analysis of stray magnetic field and frame vibrations," IEEE Transactions on Magnetics, vol. 52, no. 7, pp. 1-4, 2016, 8105304.

[8] M. Cuevas, R. Romary, J.-P. Lecointe, F. Morganti, and T. Jacq, "Noninvasive detection of winding short-circuit faults in salient Pole synchronous machine with squirrel-cage damper," IEEE Transactions on Industry Applications, vol. 54, no. 6, pp. 5988-5997, 2018.

[9] G.-J. Tang, H.-C. Jiang, Y.-L. He, and Q.-F. Meng, "Electromagnetic forces and mechanical responses of stator windings before and after rotor interturn short circuit in synchronous generators," Mathematical Problems in Engineering, vol. 2020, pp. 1-19, Article ID 5892312, 2020.

[10] Q. Meng and Y. He, "Mechanical response before and after rotor inter-turn short-circuit fault on stator windings in synchronous generator," in Proceedings of the 2018 IEEE Student Conference on Electric Machines and Systems, pp. 1-7, Huzhou, China, December 2018.

[11] L. Hao, J. Wu, and Y. Zhou, "Theoretical analysis and calculation model of the electromagnetic torque of nonsalientPole synchronous machines with interturn short circuit in field windings," IEEE Transactions on Energy Conversion, vol. 30, no. 1, pp. 110-121, 2015.

[12] W. Yucai and L. Yonggang, "Diagnosis of rotor winding interturn short-circuit in turbine generators using virtual power," IEEE Transactions on Energy Conversion, vol. 30, no. 1, pp. 183-188, 2015.

[13] L. Hao, Y. Sun, A. Qiu, and X. Wang, "Steady-state calculation and online monitoring of interturn short circuit of field windings in synchronous machines," IEEE Transactions on Energy Conversion, vol. 27, no. 1, pp. 128-138, 2012.

[14] H. Ehya and A. Nysveen, "Pattern recognition of interturn short circuit fault in a synchronous generator using magnetic flux," IEEE Transactions on Industry Applications, vol. 57, no. 4, pp. 3573-3581, 2021.

[15] P. Naderi and A. Shiri, "Rotor/stator inter-turn short circuit fault detection for saturable wound-rotor induction machine by modified magnetic equivalent circuit approach," IEEE Transactions on Magnetics, vol. 53, no. 7, pp. 1-13, 2017.

[16] M. E. Milasi, S. Afrandideh, and F. Haghjoo, "A simple fluxbased technique to specify the faulty Pole of the salient Pole synchronous machines," IEEE Transactions on Energy Conversion, vol. 36, no. 1, pp. 264-271, 2021.

[17] J. Yun, S. Park, C. Yang et al., "Comprehensive monitoring of field winding short circuits for salient Pole synchronous motors," IEEE Transactions on Energy Conversion, vol. 34, no. 3, pp. 1686-1694, 2019.

[18] W. Yucai, M. Qianqian, and C. Bochong, "Fault diagnosis of rotor winding inter-turn short circuit for sensorless synchronous generator through screw," IET Electric Power Applications, vol. 11, no. 8, pp. 1475-1482, 2017.

[19] M. Valavi, K. G. Jorstad, and A. Nysveen, "Electromagnetic analysis and electrical signature-based detection of rotor inter-turn faults in salient-Pole synchronous machine," IEEE Transactions on Magnetics, vol. 54, no. 9, pp. 1-9, 2018.

[20] Y.-G. Li, Y.-J. Zhao, L. Chen, and X. Ji, "Fault diagnosis of rotor winding inter-turn short circuit in turbine-generator based on BP neural network," in Proceedings of the 2008 International Conference on Electrical Machines and Systems, pp. 783-787, Wuhan, China, October 2008.

[21] Y. Li, Y. Sun, L. Wang, and H. Li, “The criterion on inter-turn short circuit fault diagnose of steam turbine generator rotor windings," in Proceedings of the 2007 International Conference on Electrical Machines and Systems (ICEMS), pp. 1050-1054, Seoul, Republic of Korea, October 2007.

[22] W. Shuting, L. Yonggang, L. Heming, and T. Guiji, "A compositive diagnosis method on turbine-generator rotor winding inter-turn short circuit fault," in Proceedings of the 2006 IEEE International Symposium on Industrial Electronics, pp. 1662-1666, Montreal, Canada, July 2006.

[23] Y.-L. He, W.-Q. Deng, B. Peng et al., "Stator vibration characteristic identification of turbogenerator among single and composite faults composed of static air-gap eccentricity 
and rotor interturn short circuit," Shock and Vibration, vol. 2016, Article ID 5971081, 14 pages, 2016.

[24] S. Wan, Y. Li, H. Li, and G. Tang, "The new diagnosis method of rotor winding inter-turn short circuit fault and imbalance fault based on stator and rotor vibration characteristics," in Proceedings of the 2005 International Conference on Electrical Machines and Systems, vol. 3, pp. 2207-2210, Nanjing, China, September 2005.

[25] S. Toma, L. Capocchi, and G.-A. Capolino, "Wound-rotor induction generator inter-turn short-circuits diagnosis using a new digital neural network," IEEE Transactions on Industrial Electronics, vol. 60, no. 9, pp. 4043-4052, 2013. 